\title{
FAIL SAFE, HIGH TEMPERATURE MAGNETIC BEARINGS
}

\author{
Thomas Minihan, Alan Palazzolo, Yeonkyu Kim, Shuliang Lei, Andrew Kenny, Uhn Joo Na, Randy Tucker, Jason \\ Preuss, Andrew Hunt, Bart Carter \\ Department of Mechanical Engineering \\ Texas A\&M University \\ College Station, TX, USA
}

\author{
Andy Provenza \\ NASA Glenn Research Center \\ Cleveland, Ohio, USA
}

\author{
Gerald Montague \& Albert Kascak \\ U.S. Army at NASA Glenn Research Center \\ Cleveland, Ohio, USA
}

\begin{abstract}
This paper contributes to the magnetic bearing literature in two distinct areas: high temperature and redundant actuation. Design considerations and test results are given for the first published combined $538^{\circ} \mathrm{C}$ $\left(1000^{\circ} \mathrm{F}\right)$-high speed rotating test performance of a magnetic bearing. Secondly, a significant extension of the flux isolation based, redundant actuator control algorithm is proposed to eliminate the prior deficiency of changing position stiffness after failure. The benefit of the novel extension was not experimentally demonstrated due to a high active stiffness requirement. In addition, test results are given for actuator failure tests at $399^{\circ} \mathrm{C}\left(750^{\circ} \mathrm{F}\right), 12,500 \mathrm{rpm}$. Finally, simulation results are presented confirming the experimental data and validating the redundant control algorithm.
\end{abstract}

\section{INTRODUCTION}

Large advancements in gas turbine engine efficiency mandate continuous operation at temperatures substantially higher than the present generation. Rotordynamic stability and response present challenges in these temperature regimes due to limitations in conventionally lubricated bearings and dampers. A host of innovative devices ranging from damping seals to dry friction dampers, foils bearings and magnetic bearings (MB) have been developed as possible solutions. Magnetic bearings possess distinct advantage over the alternate solutions in their ability to work at high altitudes (no air requirements as for foil bearings to adapt to various load conditions - take off, landing, maneuvers, etc.). The present manuscript provides results from recent milestone testing achieved at NASA GRC for combined high speed/high temperature MB operation. In addition a novel extension of the flux isolation approach to redundant $\mathrm{MB}$ actuator control is proposed.

\section{NOMENCLATURE}

$G_{i j} \quad$ Proportional gain $(\mathrm{i}, \mathrm{j})=(\mathrm{x}, \mathrm{y})$

$\underline{K}$ pos $\quad$ Position stiffness matrix

$\widetilde{K} \quad$ Isolated opposing $\mathrm{C}$ core position stiffness

$K_{p o s}^{N F} \quad \underline{K}_{p o s}$ for un-failed state

$\underline{Q}_{a b c} \times \mathrm{y}$ control voltage to $a b c$ control voltage distribution matrix

$\underline{V}_{a b c} \quad$ Control voltage to a, b, c axes power amplifiers

\section{LITERATURE REVIEW}

A significant number of research papers have recently appeared dedicated to high temperature $M B$ development. Such areas as electrical insulation, load capacity and thermal growth have formed the focus of these efforts.

Ohsawa, et. al [1] developed and tested a MB at $399^{\circ} \mathrm{C}\left(750^{\circ} \mathrm{F}\right)$ on an $80 \mathrm{~kg}(176 \mathrm{lb}), 12,000 \mathrm{rpm}$ blower rotor. A $1500 \mathrm{hr}$ endurance test was successfully completed with the high temperature magnetic bearing (HTMB). Kondoleon and Kelleher [2] investigated the magnetic and structural integrity of magnetic bearing laminate materials up to $538^{\circ} \mathrm{C}\left(1000^{\circ} \mathrm{F}\right)$. Satisfactory characteristics were obtained for Hiperco 50, Hiperco

This is a preprint or reprint of a paper intended for presentation at a conference. Because changes may be made before formal publication, this is made available with the understanding that it will 
50HS and Rotelloy 5. Mekhiche, et. al. [3] have developed an 8 pole magnetic bearing with capability to reach $593^{\circ} \mathrm{C}\left(1100^{\circ} \mathrm{F}\right)$ and operate at $50,000 \mathrm{rpm}$, however, only room temperature results were reported. $\mathrm{Xu}$, et. al. [4] have developed and tested a $538^{\circ} \mathrm{C}$ $\left(1000^{\circ} \mathrm{F}\right), 8$ pole $\mathrm{MB}$ and position sensor system. Only static tests were performed at the time of the paper's publication. Scholten [5] performed a simulation study to define maneuver load requirements and Hilbner and Rosado [6] identified benefits and necessary modifications for implementing HTMB's in gas turbine engine applications.

The two areas to be discussed in the present paper are the HTMB magnetic bearing construction and also the novel redundant control algorithm used with it for magnetic levitation. This algorithm provides fault tolerance by maintaining decoupled, linearized magnetic suspension, control forces even after failure(s) of coil within the actuator or power amplifiers driving current through the coils. Previous work on fault tolerant magnetic bearing actuators focused on two general approaches: flux coupling and flux isolation. The former approach as developed by Meeker, Masler, et. al. at the University of Virginia $[7,8,9]$ changes fluxes in all failed and unfailed poles to provide spatially $(x, y)$ uncoupled and linearized control forces, after a failure. The fluxes remained coupled between all poles in this approach and the maximum flux density limits the load capacity if it exceeds the material saturation limit. A derivative approach that simultaneously minimizes the Euclidean norm of the pole flux densities was developed by $\mathrm{Na}$ and Palazzolo at Texas A\&M [10]. The flux isolation method, initially proposed by Storace, Lyons, et. al. [11,12] at General Electric, employs a redundant control axis so that two of the 3 control axes, in their 12 pole actuators, are sufficient to provide the demanded control forces. Each axis is composed of two opposing C-Cores that have the same, centered actuator, bias flux and equal and opposite control fluxes. Both flux isolation and flux coupling approaches to fault tolerant $\mathrm{MB}$ actuators appear in the cited literature. The benefit of the former is its simplicity in possessing only 3 current redistribution matrices, and its lower hardware requirements $(6$ power amplifiers and no decoupling choke). The drawbacks of the former include less robustness for many pole failure combinations and lower load capacity. The choice of the proper approach for a given application should be based on the level of fault tolerance required and consideration of the reliability of the power amplifiers and decoupling choke, as well as the actuator's coils.

Significant contributions are provided in the present paper for both the HTMB and fail-safe/redundant control areas. Specifically the HTMB performance data appears to be the first published accounts of an actual rotating test $(10,000 \mathrm{rpm})$ at $538^{\circ} \mathrm{C}\left(1000^{\circ} \mathrm{F}\right)$, i.e. previous tests were performed only statically at temperatures above $399^{\circ} \mathrm{C}\left(750^{\circ} \mathrm{F}\right)$. It is well known that looseness of parts on a spinning shaft may cause rotordynamic instability due to internal friction and parametric excitation. The success of the rotating test confirmed that the rotor lamination fits were effective in preventing anomalous vibration at high speed and temperature. It is also notable that this was accomplished with a twelve pole actuator that could be used with either a flux isolation or flux coupling approach to redundant actuation. A novel extension of the flux isolation method for redundant actuation is also presented, in which the deficiency of coupled $(x, y)$ position stiffnesses after failure is eliminated.

\section{REDUNDANT CONTROL ALGORITHM}

A redundant control algorithm was formulated to provide stable control during control axes failures. Specifically, the purpose of the redundant control algorithm is to preserve control forces and effective stiffness following a single axis failure. This was accomplished by developing current distribution and cross-coupled gain matrices for each of the three failure cases.

The 3 axis, isolated flux proposed in $[11,12]$ preserves control forces following a single axis failure. This method employs the following distribution matrices to convert $x y$ control signals into control signals along the 3 redundant axes $(a, b, c)$, which are in turn routed to power amplifiers (Figure 1).

12 Pole Radial Magnetic Bearing Control Block Diagram

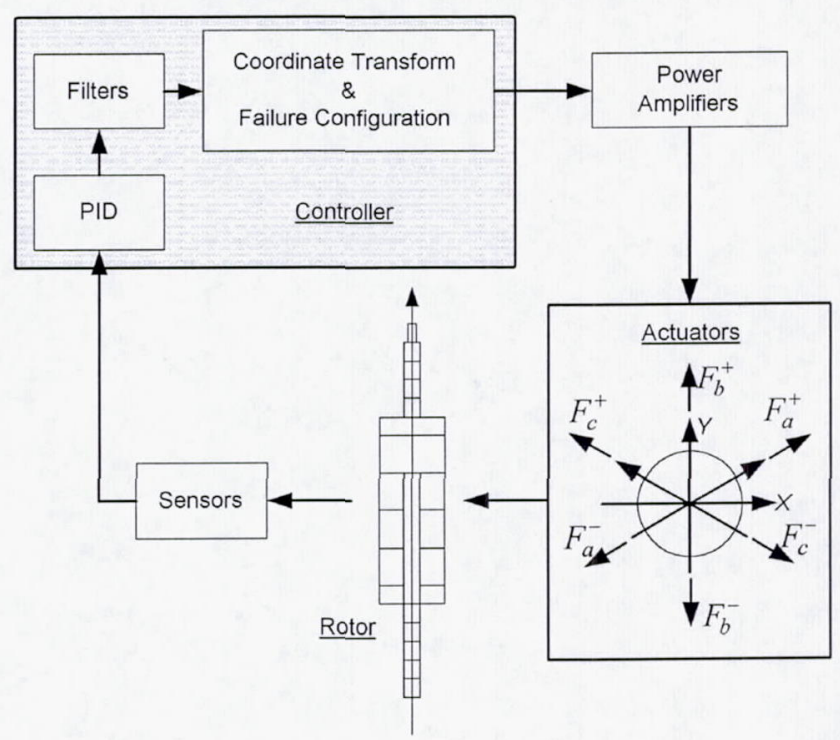

Figure 1. Feedback Control Block Diagram. 
These matrices are obtained from a least squares minimization of control effort.

$$
\underline{V}_{a b c}=\underline{Q}_{a b c}\left\{\begin{array}{l}
V_{c x} \\
V_{c y}
\end{array}\right\}
$$

$$
\begin{array}{ll}
\text { No failure } & \underline{Q}_{a b c}=\left[\begin{array}{cc}
.577 & .333 \\
0 & .667 \\
-.577 & .333
\end{array}\right] \\
\text { "a" axis failure } & \underline{Q}_{a b c}=\left[\begin{array}{cc}
0 & 0 \\
.577 & 1.0 \\
-1.155 & 0
\end{array}\right] \\
\text { "b" axis failure } & \underline{Q}_{a b c}=\left[\begin{array}{cc}
.577 & 1 \\
0 & 0 \\
-.577 & 1
\end{array}\right] \\
\text { "c" axis failure } & \underline{Q}_{a b c}=\left[\begin{array}{cc}
1.155 & 0 \\
-.577 & 1 \\
0 & 0
\end{array}\right]
\end{array}
$$

Although control forces are preserved, position stiffness related forces are changed by the failure of a control axis and are not automatically compensated by the above redistribution of currents, i.e. a control law change in the PID level must also be activated. The following summarizes the change in position stiffness with axis failure. Let $\widetilde{K}$ represent the position stiffness along any control axis ( $a, b, c)$ prior to failure. The position stiffness matrix for the $x y$ axes has the following form;

$$
\begin{aligned}
& \underline{K}_{p o s}=\left[\begin{array}{cc}
K_{x x}^{p o s} & K_{x y}^{p o s} \\
K_{y x}^{p o s} & K_{y y}^{p o s}
\end{array}\right] \\
& \text { No failure } \quad \underline{K}_{\text {pos }}^{N F}=\tilde{K}\left[\begin{array}{cc}
1.5 & 0 \\
0 & 1.5
\end{array}\right] \\
& \text { "a" axis failure } \quad \underline{K}_{\text {pos }}=\tilde{K}\left[\begin{array}{cc}
0.75 & -.433 \\
-.433 & 1.25
\end{array}\right] \text { (8) } \\
& \text { "b" axis failure } \quad \underline{K}_{\text {pos }}=\tilde{K}\left[\begin{array}{cc}
1.5 & 0 \\
0 & 1.5
\end{array}\right] \\
& \text { "c" axis failure } \quad \underline{K}_{p o s}=\tilde{K}\left[\begin{array}{cc}
.75 & .433 \\
.433 & 1.25
\end{array}\right]
\end{aligned}
$$

A control law algorithm for maintaining the desired effective stiffness before and after failure and canceling cross-coupled position stiffness is outlined for PD control. Active magnetic bearing properties can be represented by effective stiffness and damping. The effective stiffness is comprised of the active (control) stiffness, $K^{a c t}$, and position stiffness, $K^{p o s}$ as shown in equation (11).

$$
K^{e f f}=K^{a c t}+K^{p o s}
$$

Let $K^{\text {cur }}$ represent the current stiffness for a single, opposing, $C$ core pair, then the active stiffness is given by equation (12).

$$
K^{a c t}=G_{p} K^{c u r}
$$

In order to maintain the desired effective stiffness, the proportional gains after failure $\hat{G}_{p i j}$ are related to their counterparts before failure $G_{p i j}$ by:

$$
\hat{G}_{p i j}=\frac{G_{p i j} K^{c u r}+K_{p o s, i j}^{N F}-K_{p o s, i j}}{K_{c u r}}
$$

where

$$
\begin{aligned}
& (i, j)=(1,1)=(x, x) \\
& (i, j)=(1,2)=(x, y) \\
& (i, j)=(2,1)=(y, x) \\
& (i, j)=(2,2)=(y, y)
\end{aligned}
$$

Note that $\hat{G}_{p i j}$ is fully populated whereas $G_{p i j}$ is typically diagonal for uncoupled SISO type control. This necessitates a proportional cross gain in the PD stage of Figure 1 to cancel the cross-coupled position stiffness after an axis failure. The effects of changes in the position stiffness matrix after failure can also be minimized by selecting high controller gains such that the active stiffness is the dominant component. Although the form of equation (13) is quite simple relative to more analytically based algorithms, i.e. $\mathrm{H}_{\infty}$, fuzzy logic, sliding mode, it correctly compensates for the position stiffness changes with failure, and may be easily implemented in an industrial PID based controller. Its implementation does require alteration to an uncoupled PID controller coding due to the xy cross coupled gain and adaptation with failure.

\section{BEARING DESIGN}

The HTMB stator (Figure 2) has 12 poles and is composed of 214 laminates, each $.35 \mathrm{~mm}$ (14mil) thick, and made of heat-treated Hiperco 50A. The pole width is selected to yield the maximum force as determined by the pole's cross sectional area, maximum current available and number of turns. The design load capacity based on a saturation B of 2.0T and activation of 4 poles is $1500 \mathrm{~N}(337 \mathrm{lb})$. This approximation ignores fringing and material path reluctance. The rotor lamination's ID and $O D$ are $6.0 \mathrm{~cm}(2.36 \mathrm{in})$ and $7.45 \mathrm{~cm}$ (2.93in), 
respectively, and the air gap at the poles is $0.45 \mathrm{~mm}$ (17.7mil).
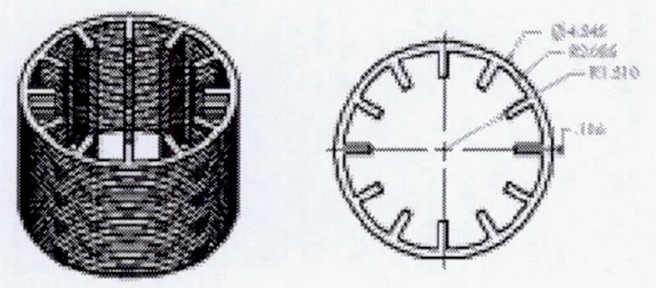

Figure 2. Stator Lamination Stack.

The coils are wound from nickel clad copper and are potted with a magnesium oxide compound. Each coil is hand wound, cured at $121^{\circ} \mathrm{C}\left(250^{\circ} \mathrm{F}\right)$ for 3 hours and retained on its pole by metal pins (Figure 3 ). The resistance of each coil is measured vs. temperature up to $815^{\circ} \mathrm{C}\left(1500^{\circ} \mathrm{F}\right)$, as shown by Figure 4 . Along with hipotting, this has proven to be a good indicator of coil integrity.

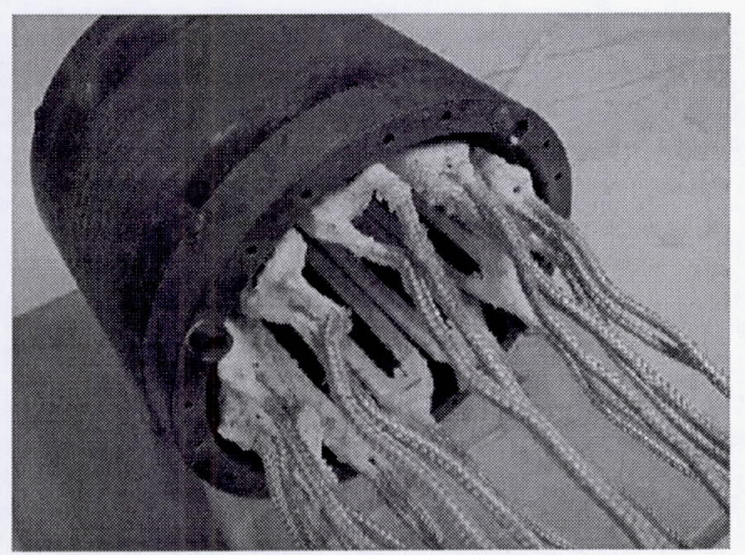

(a)

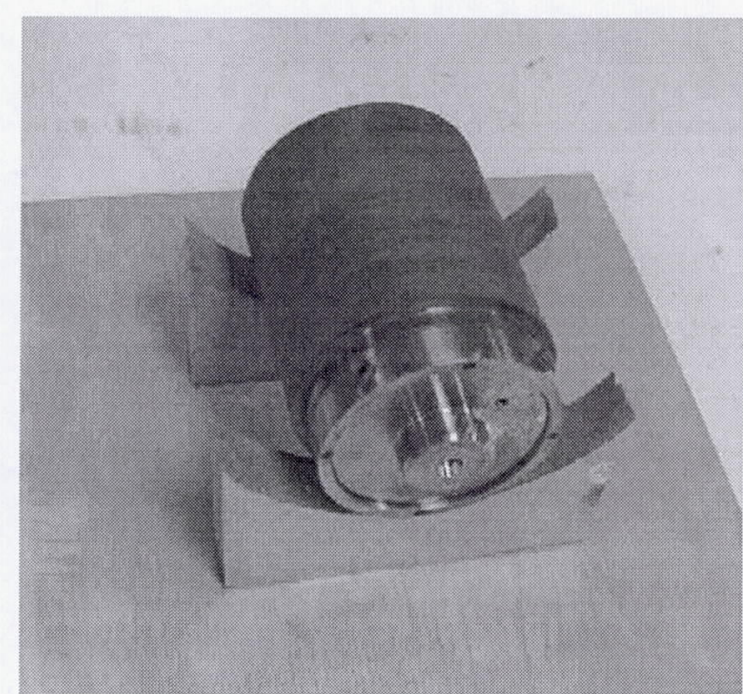

(b)

Figure 3. HTMB Stator (a) and (b) Rotor.

EFFECTS OF TEMPERATURE ON COIL RESISTANCE

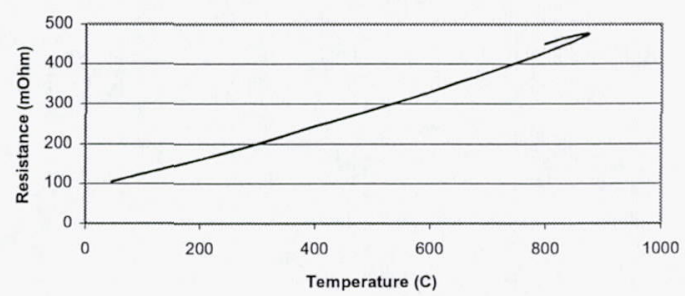

Figure 4. Resistance vs. Temperature for HTMB Coil.

For a flux isolation ( $\mathrm{C}$ core) approach to redundant magnetic bearings it is essential that the flux in any given $C$ core does not leak to other $C$ cores even if 1 or more of the $\mathrm{C}$ cores are turned off. A 3D FE field analysis was performed with only the bias flux density circulating in all C-cores. This study confirmed the flux isolation characteristic, as demonstrated by Figure $5 \mathrm{a}$ (all C-cores active) and Figure $5 \mathrm{~b}$ (5 out of $6 \mathrm{C}$-cores active). It is clear from Figure $5 b$ that there is very little flux leakage into the failed $\mathrm{C}$-core from the active $\mathrm{C}$-cores, hence demonstrating continued isolation of the C-core fluxes after failure. The model in this figure has a smaller $\mathrm{L} / \mathrm{D}$ ratio than the actual HTMB rotor in Figure 3, however the isolation results should still be applicable. 

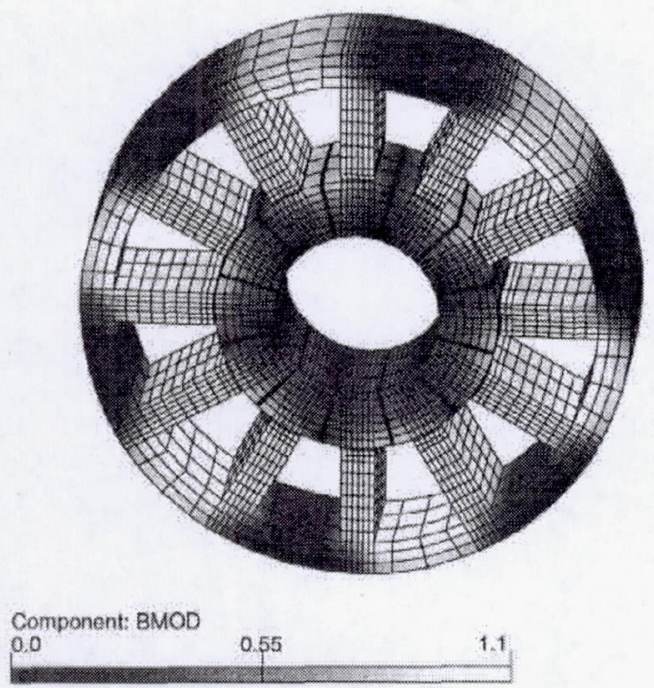

(a)

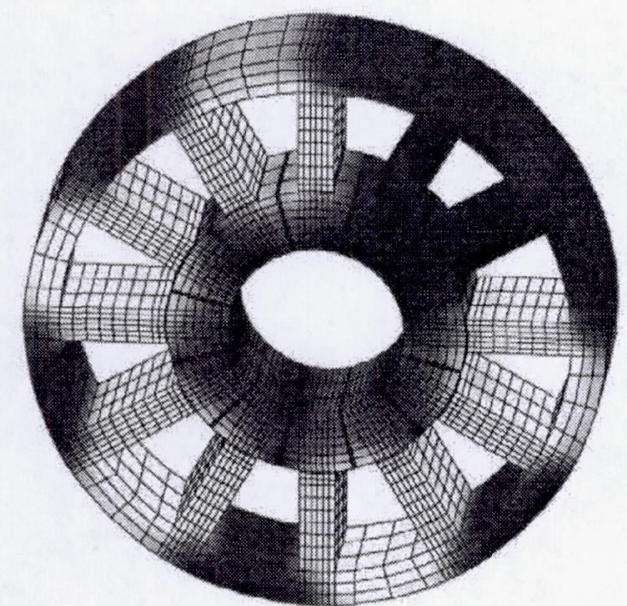

Component: BMOD

$0.000987516 \quad 0.550494$ 1.1

(b)

Figure 5. Three Dimensional FEA Prediction of Flux Field in (a) Unfailed and (b) Failed HTMB.

\section{HTMB COMPONENT TESTING (STATIC)}

A test fixture was constructed to measure load capacity of the magnetic bearing vs. temperature under non-rotating condition (Figure 6). Strain gage load cells support the stator and measure the force it exerts on a dummy rotor shaft which is centered rigidly with dead centers. A cooling jacket is employed to protect the load cells by removing heat conducted from coil heaters wrapped around the OD of the back iron (Figure 7). The assembled $\mathrm{MB}$ is encapsulated in high temperature insulation to retain heat in the rotor, stator and coil components, and current is driven through the coil via PWM, servo power amplifiers. Figure 8 shows plots of MB force vs. current at 6 selected temperatures in the range from ambient to $538^{\circ} \mathrm{C}\left(1000^{\circ} \mathrm{F}\right)$. The force reduction with increased temperature results from the temperature dependence of the $\mathrm{B}-\mathrm{H}$ characteristics for the stator and rotor lamination stack material. The temperatures in this figure are measured between poles, on the inside surface of the stator lamination stack, at the center of the bearing. It is interesting to note that the rotor and coil temperatures were measured to be $530^{\circ} \mathrm{C}$ $\left(986^{\circ} \mathrm{F}\right)$ and $690^{\circ} \mathrm{C}\left(1274^{\circ} \mathrm{F}\right)$, respectively, with a stator temperature of $543^{\circ} \mathrm{C}\left(1010^{\circ} \mathrm{F}\right)$ and current of $12 \mathrm{amps}$. Figure 9 shows a view of the bearing following the component testing.

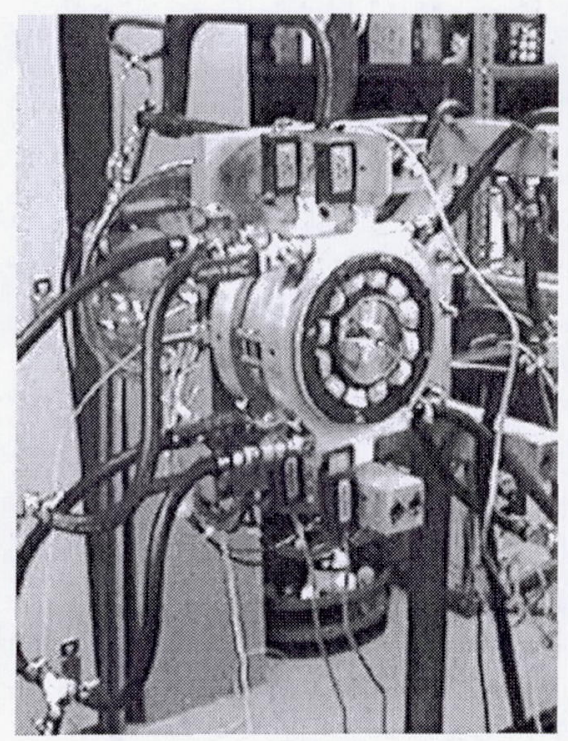

Figure 6. Test Fixture for Static Force Temperature Test of HTMB. 


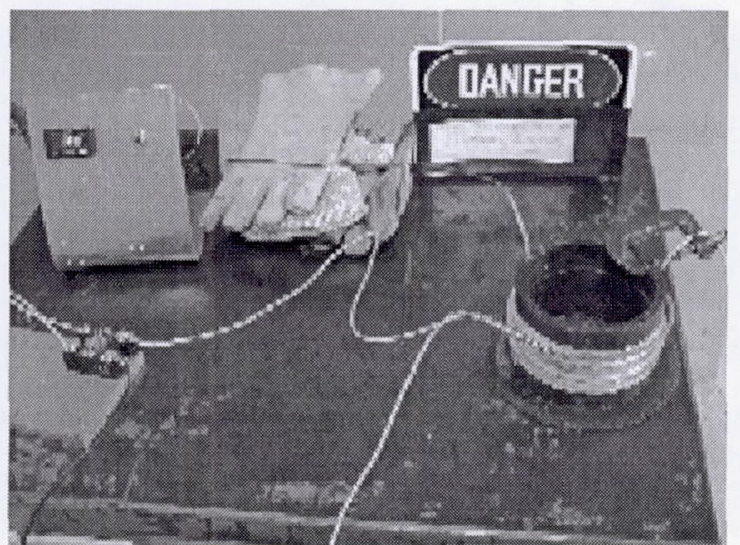

Figure 7. Coil Heater Wrapped Around Stator for Temperature Controller.

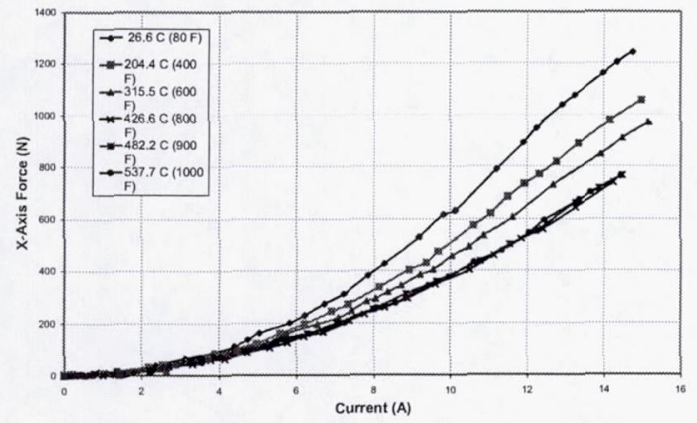

Figure 8. Magnetic Bearing Forces vs. Current and Temperature for Static Testing.

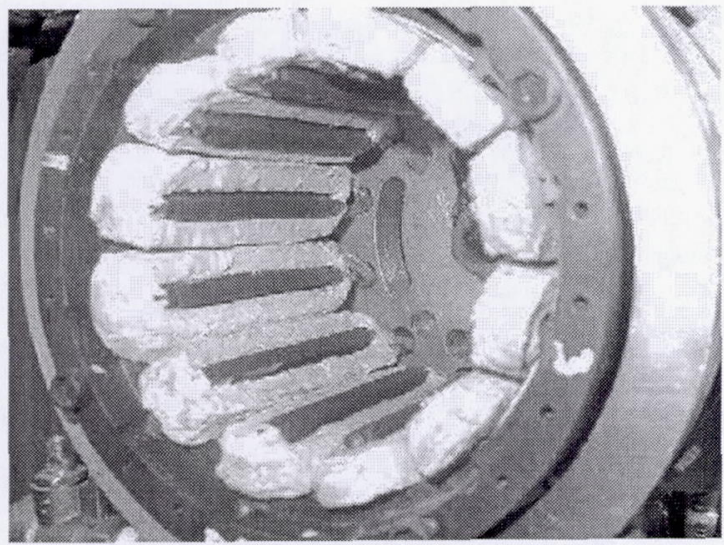

Figure 9. Close-up View of HTMB Following Static Load High Temperature Test.

\section{HTMB SYSTEM TEST (DYNAMICS)}

Band type heaters and insulators were wrapped around the HTMB stator, which was then rigidly fixed in the rotating test rig shown in Figure 10. The shaft weight is approximately $114 \mathrm{~N}(25.6 \mathrm{lb})$, and its CG is located at the HTMB centerline in the axial direction. The shaft bearing at the turbine driver end is a duplex pair consisting of two ABEC 7, angular contact bearings, oriented to provide radial support and an angular (moment) release. This bearing set was lubricated with Krytox grease for high temperature operation. Eddy current position sensors are air-cooled and are positioned about $5 \mathrm{~cm}$ (1.97in) axially offset from the HTMB ends. Opposing pairs are employed to compensate for thermal expansion of the shaft. The auxiliary (backup) bearing is located at the outboard end of the shaft, is composed of another ABEC 7, duplex pair, is lubricated with Krytox grease and has a $0.175 \mathrm{~mm}$ (6.9mil) radial gap. Currents to the HTMB are supplied by six $160 \mathrm{~V}$, pulse width modulated, power amplifiers. The shaft position signals are routed to a digital control unit, which in turn produces control signals for the power amplifier. The rig was initially spun to $14,000 \mathrm{rpm}$ at room temperature with magnetic suspension provided by the HTMB. A similar test at $538^{\circ} \mathrm{C}\left(1,000^{\circ} \mathrm{F}\right)$ (stator) and with a maximum speed of $10,000 \mathrm{rpm}$ was also performed. The corresponding coil and turbine end bearing temperatures were $677^{\circ} \mathrm{C}\left(1250^{\circ} \mathrm{F}\right)$ and $163^{\circ} \mathrm{C}$ $\left(325^{\circ} \mathrm{F}\right)$, respectively.

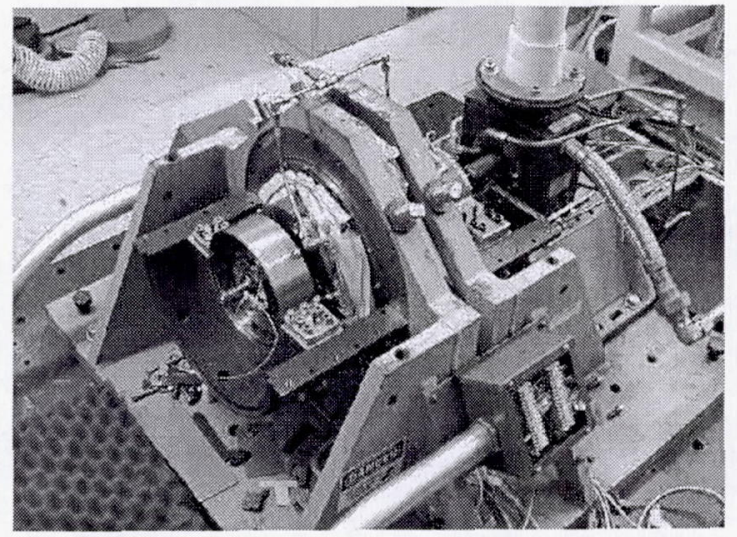

Figure 10. Photograph of Rotating Test Rig at NASA GRC with Test Bearing.

\section{FAILSAFE TESTING}

Failsafe tests were conducted to evaluate the redundant control algorithm at temperature and speed. Each of the three control axes were individually failed and the response was recorded using a Nicolet data acquisition system. The results indicate that the 
redundant control algorithm provides stable control following any single axis failure event.

The failsafe tests were conducted at $399^{\circ} \mathrm{C}\left(750^{\circ} \mathrm{F}\right)$ and 12,500rpm. A digital switchbox was used to initiate a failure along a user-selected control axis. The switch action opens the control output circuit to the coil and simultaneously sends a TTL to the digital controller, which triggers the redundant control algorithm.

The results shown in figures 11 through 15, indicate that stable control is maintained during the single axis failure events. Figures 11-13 show the test rig data for failures of the a-axis. Figure 11 displays the servoamplifier currents arranged in their respective geometric positions. The redistribution of the control currents is visible when the switchbox de-energizes both a-axis coils. Figure 12 shows the displacements at the rotor CG and the outboard catcher bearing, where the failure in indicated by the vertical line. Notice the glitch at the instant of coil failure. Figure 13 exhibits the rotor orbits, also at the CG and outboard catcher bearing. Although the control forces are conserved, there is a noticeable effect on the orbit geometry.

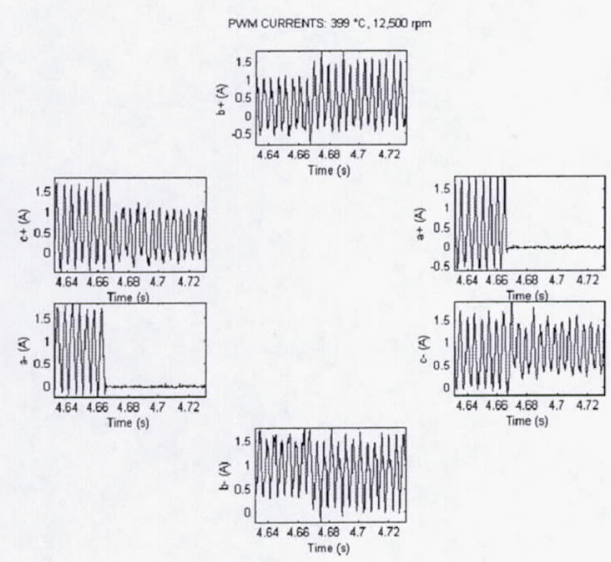

Figure 11. Coil Currents, a-Axis Failure

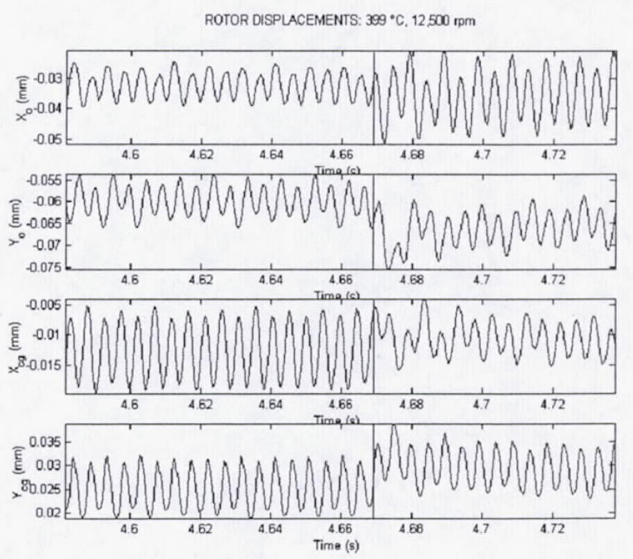

Figure 12. CG and Outboard Displacements, aAxis Failure
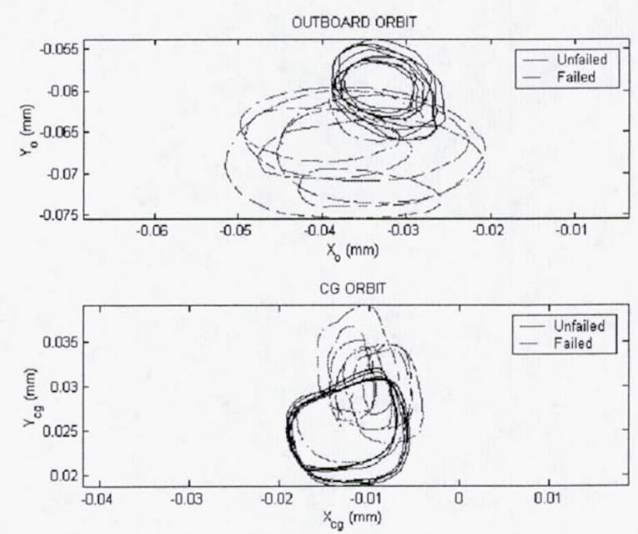

Figure 13. CG and Outboard Orbits, a-Axis Failure

Test results validate the redundant control algorithm during all three single axis failure scenarios. It should be noted that control is also maintained when the failed axes are re-energized. Similar results were obtained with both $b$ and $c$ axes failures as seen by figures 14 and 15. 

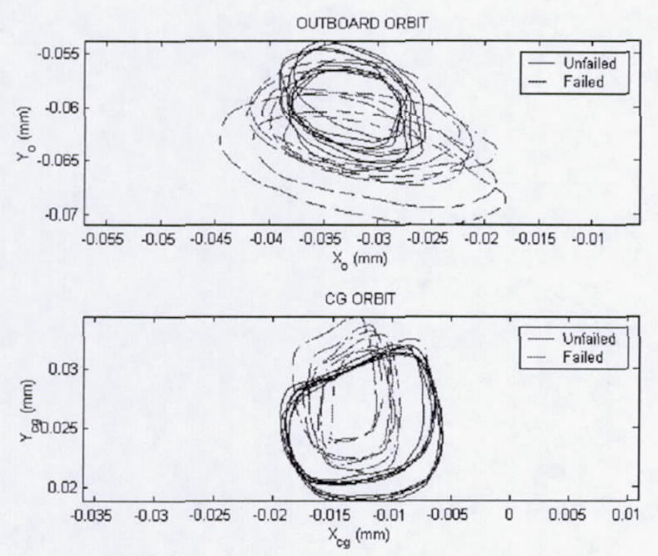

Figure 14. CG and Outboard Orbits, b-Axis Failure
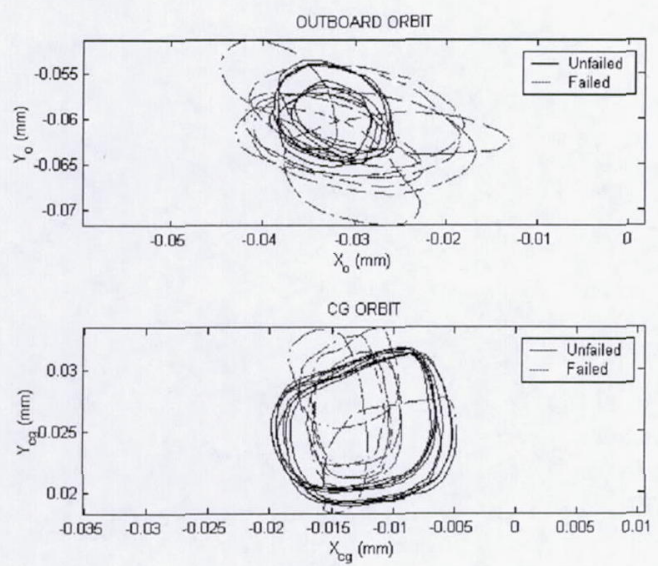

Figure 15. CG and Outboard Orbits, C-Axis Failure

\section{ANALYTICAL ANALYSES/SIMULATIONS}

An analytical model was developed for theoretical analysis and simulation using Matlab in an effort to simulate and verify the redundant control theory. A 4 DOF per node finite element model for the rotor assembly combined with a classical controller was employed. Several analyses were conducted including eigenvalues, steady-state imbalance response, transient imbalance and levitation simulations.

The finite element rotor model, depicted in Figure 16, was created using a 1-D mesh of sixteen Euler beam elements. Four degrees of freedom per node were accomplished by eliminating the axial and torsional dynamics. The actuator lamination stack was included in the elemental mass but not as additional bending stiffness. This is illustrated in the figure by the elements that possess two radial divisions, the inner representing the stiffness diameter and the outer the mass diameter. Both linearized and nonlinear magnetic actuator force relations were used for comparison purposes. Gravitational and gyroscopic effects were included in the model. A classical PD controller with lead-lag compensation was designed to be identical to the actual digital controller. A lag compensator was used in lieu of integral control to eliminate steady-state error. Coordinate transformations discussed previously were used to output control signals to the actuator's $a b c$ control axes. Control axis failures were simulated by discontinuing current to the failed axis coils and applying the appropriate transformation matrix at a pre-selected time step.

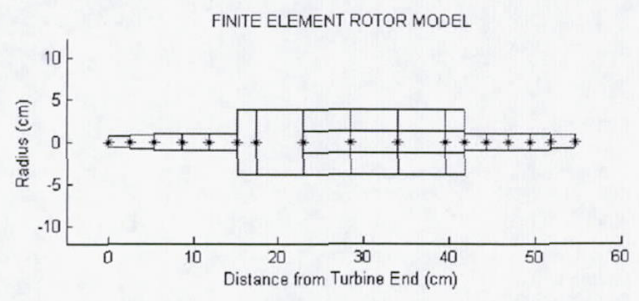

Figure 16. FE Model of Test Rotor

Several analyses were conducted including closedloop eigenvalues, steady-state imbalance and transient simulations. Eigenvalue analysis closely predicted the two experimental critical speeds below 20,000 rpm, approximately $6,300 \mathrm{rpm}$ and $14,200 \mathrm{rpm}$. Although the state of imbalance was not experimentally measured axis failure simulations were performed with a static imbalance eccentricity, $u=2.54 \mathrm{e}-3 \mathrm{~mm}(0.1 \mathrm{mil})$. The steady-state response to imbalance is given in Figure 17. Transient simulations of the response to imbalance indicate that stable control is maintained in the event of a c-axis failure (Figures 18 and 19). As shown, the failure has a negligible effect on the displacements and orbit pattern. The cross-coupled stiffness cancellation is not activated in this scenario because the active stiffness is an order of magnitude higher than the position stiffness. In order to illustrate the effects of the cross coupled stiffness cancellation, the proportional gains must be lowered from their nominal values to reduce the active stiffness to the same order of magnitude as the position stiffness. 


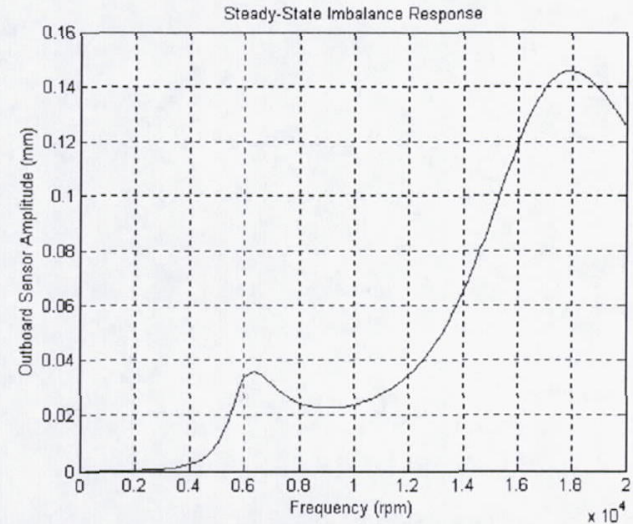

Figure 17. Steady-State Imbalance Response
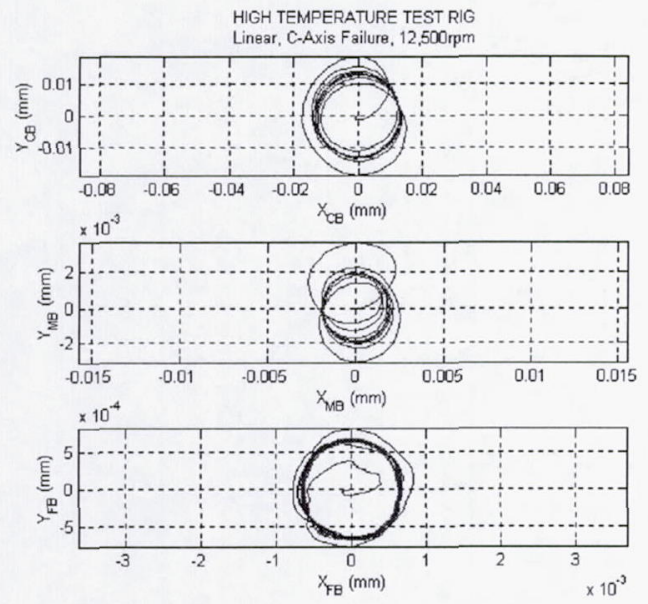

Figure 18. C-Axis Failure Simulation
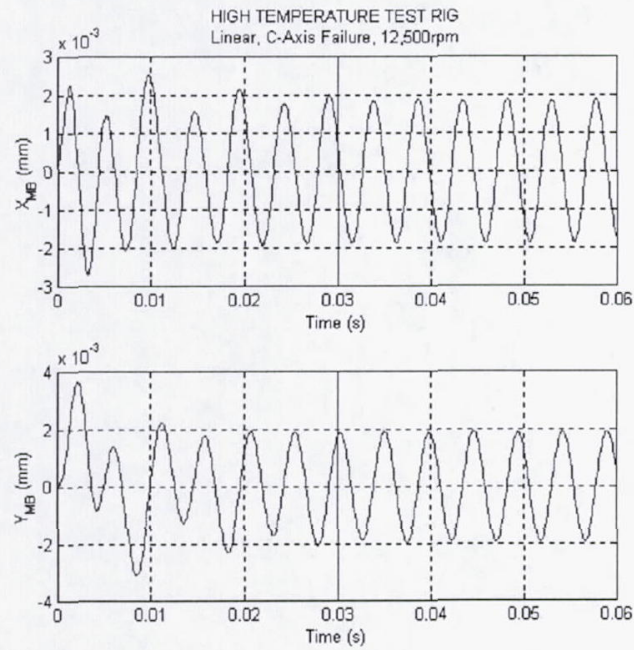

Figure 19. C-Axis Failure Simulation

\section{SUMMARY/FUTURE WORK}

This paper presents results of development efforts for a novel HTMB. The bearing exhibited good load capacity, although it is degraded somewhat at higher temperatures. Total run time on this bearing above $371^{\circ} \mathrm{C}\left(700^{\circ} \mathrm{F}\right)$ to this date is 27.5 hours. A novel extension of the 3 control axis, isolated flux, redundant control algorithm is presented to compensate for position stiffness changes that occur after failure. The control algorithm was verified through simulations and experiments. Dynamic tests at temperature and speed indicate stable control is maintained during single event axis failures. Although the benefit of the novel extension, i.e. compensation for position stiffness change, was not experimentally demonstrated due to a high active stiffness requirement for these tests, It is felt that it may be beneficial for other applications, e.g. a vertical rotor. A high load $(4450 \mathrm{~N}(1000 \mathrm{lb})$ capacity)/high temperature $538^{\circ} \mathrm{C}\left(1000^{\circ} \mathrm{F}\right)$ magnetic bearing is nearly completed and will be tested in the next several months at NASA GRC (Figure 20).

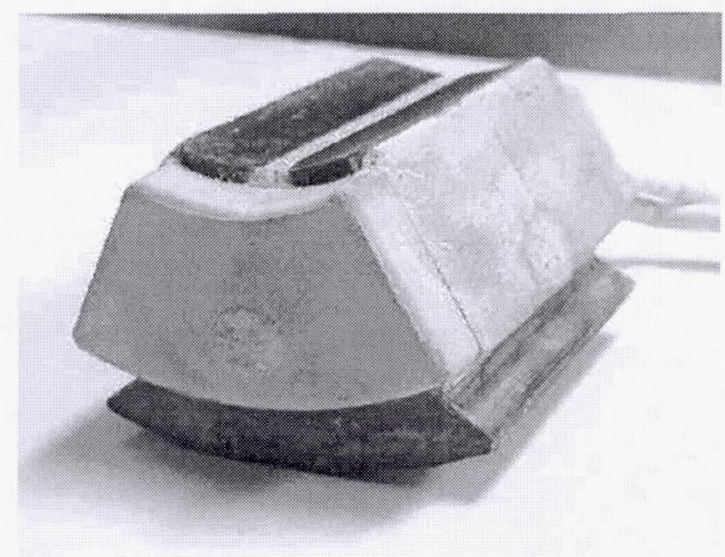

Figure 20. High Load/High Capacity C-Core

\section{ACKNOWLEDGMENTS}

The authors gratefully acknowledge funding of this project by the Machinery Dynamics Branch of NASA Glenn (NRA-GRC-99-02), and the excellent technical support of Mr. John Poles of NASA Glenn in the area of Power Electronics. The authors also thank Tom Calvert, Lynn Petersen and Glen Bell of the NAVY NSWC for their co-funding of our research on redundant magnetic actuators (BAA 97-030).

\section{REFERENCES}

1. Ohsawa, M., Yoshiolo, K., Ninomiya, H., et. al., "High Temperature Blower for Molten Carbonate Fuel Cell Supported By Magnetic Bearings," 
2. Konololeon, A. and Kelleher, W., "Soft Magnetic Alloys for High Temperature Radial Magnetic Bearings," $7^{\text {th }}$ Inter. Symp. on Magnetic Bearings, August 23-25, 2000, ETH, Zurich pp. 111-116.

3. Mekhiche, M., et. al. " $50 \mathrm{~K} \mathrm{rpm}, 1100^{\circ} \mathrm{F}$ Magnetic Bearings for Jet Turbine Engines," $7^{\text {th }}$ Inter. Symp. on Magnetic Bearings, August 23-25, 2000, ETH, Zurich, pp. 123-128.

4. Xu, L., Wanh, L. and Schweiter, G., "Development of Magnetic Bearings for High Temperature Suspension," $7^{\text {th }}$ Inter. Symp. on Magnetic Bearings, August 23-25, 2000, ETH, Zurich pp. 117-121.

5. Scholten, J. R., 1997, "A Magnetic Bearing Suspension System for High Temperature Gas Turbine Applications: Control System Design," 1997 IGTI Conf., Paper 97-GT-29.

6. Hibner, D. and Rosado, L., 1992, "Feasibility of Magnetic Bearings for Advanced Gas Turbine Engines," Magnetic Bearings and Dry Seal Symp., 1992, Calgary, Revolve Corp.

7. Maslen, E.H. and Meeker, D.C., 1995, "Fault Tolerance of Magnetic Bearings by Generalized Bias Current Linearization," Magnetics - Transactions of the IEEE 31, pp. 2304-2314.

8. Meeker, D.C., 1996, "Optimal Solutions to the Inverse Problem in Quadratic Magnetic Actuators," Ph. D. Dissertation, Mechanical Engineering, University of Virginia.

9. Maslen, E.H., Sortoe, C.K., Gillies, G.T., Williams, R.D., Fedigan, S.J. and Aimone, R.J., 1999, "A Fault Tolerant Magnetic Bearings," Journal of Engineering for Gas Turbines and Power - Transactions of ASME 121, pp. 504-508.

10. $\mathrm{Na}$, U.J. and Palazzolo, A.B., "Optimized Realization of Fault-Tolerant Heteropolar Magnetic Bearings," 2000, ASME J. of Vibrations, Vol. 122, July 2000, pp. 209-221.

11. Lyons, J.P., Preston, M.A., Gurumoorthy, R., Szczensy, P.M., "Design and Control of a Fault-Tolerant Active Magnetic Bearing System for Aircraft Engine," Proceedings of the $4^{\text {th }}$ International Symp. on Magnetic Bearings, 1994, ETH, Zurich, pp. 449-454.

12. Storace, A., et. al., 1994, "Integration of Magnetic Bearings in the Design of Advanced Gas Turbine Engines," $2^{\text {nd }}$ Inter. Symp. on Magnetic Suspension Technology, Seattle, WA, NASA Conf. Pub. 3247, pp. 431-450. 